\title{
COMPARISON AND CORRELATION BETWEEN ARTERIAL AND CAPILLARY BLOOD GAS VALUES IN MECHANICALLY VENTILATED ADULTS
}

\author{
Arun Rath', Bhabani Sankar Pati2, Shakti Bedanta Mishra ${ }^{3}$
}

${ }_{1}^{1}$ Assistant Professor, Department of Anaesthesiology and Critical Care, IMS and Sum Hospital, Bhubaneswar, Odisha. ${ }^{2}$ Assistant Professor, Department of Anaesthesiology and Critical Care, IMS and Sum Hospital, Bhubaneswar, Odisha. ${ }^{3}$ Associate Professor, Department of Anaesthesiology and Critical Care, IMS and Sum Hospital, Bhubaneswar, Odisha.

\section{ABSTRACT}

\section{BACKGROUND}

The essence of critical care medicine is the application of physiological principles to the care of seriously ill patients. Arterial puncture apart from being painful and technically difficult carries the risk of complications like local haematoma, infection, thrombosis, embolisation or ischaemia of the digits.

The purpose of this study was to investigate the correlation between simultaneous arterial blood gas and arterialised earlobe blood samples.

\section{MATERIALS AND METHODS}

This was a descriptive study. Blood sample was collected simultaneously from left radial artery and ear lobe. The ear lobe was arterialised using hot mops for 3 minutes, a bold puncture was made with a lancet and blood was collected in pre-heparinised capillary tubes anaerobically without squeezing the ear lobe. Arterial sample was collected from the left radial artery in preheparinised $2 \mathrm{~mL}$ syringes by 22-G needle after modified Allen's test. All samples were collected from the patients after 12 hours of initiation of mechanical ventilation and the samples were analysed using a point-of-care blood gas analyser.

\section{RESULTS}

A total of 82 paired samples were analysed. The baseline demographics were comparable. On Bland-Altman's analysis of $\mathrm{pH}$ the mean difference was 0.01, while Limits of Agreement (LOA) were between +0.07 to -0.05 units and all dates were between two standard deviations. On Bland-Altman analysis for $\mathrm{PaO}_{2}$ the mean difference was $18.6 \mathrm{mmHg}$, while the limits of agreement (LOA) were between $14.2 \mathrm{mmHg}$ to $23.0 \mathrm{mmHg}$ and all the data were with two standard deviations. On Bland-Altman analysis for pCO and bicarbonate, we found scattered beyond two standard deviations. Regression analysis was done to find the convection formula for capillary to arterial. $\mathrm{PaO}_{2}$, it was $0.9\left(\mathrm{pCO}_{2}\right)+32.6 \mathrm{mmHg}$.

\section{CONCLUSION}

Capillary blood gas analysis can be used to estimate the $\mathrm{pH}$ and $\mathrm{PaO}_{2}$, but may not be of value for calculating $\mathrm{pCO}_{2}$ or bicarbonate.

\section{KEYWORDS}

ABG- Arterial Blood Gas, CBG- Capillary Blood Gas, Oxygen Saturation, $\mathrm{PaO}_{2}$, $\mathrm{pCO}_{2}$, Base Excess, (A-a) 02 Gradient, Serum Na, K, $\mathrm{HCO}_{3}$.

HOW TO CITE THIS ARTICLE: Rath A, Pati BS, Mishra SB. Comparison and correlation between arterial and capillary blood gas values in mechanically ventilated adults. J. Evolution Med. Dent. Sci. 2018;7(12):1454-1457, DOI: 10.14260/jemds/2018/330

\section{BACKGROUND}

The essence of critical care medicine is the application of physiologic principles to the care of seriously ill patients. State-of-the-art devices play a crucial role in providing moment to moment information about key circulatory and respiratory physiologic variables, their derangement by disease and response to intervention. Blood gas analysis is the gold standard for assessment, monitoring, evaluation of acid base status and adequacy of oxygenation and ventilation of patients suffering a wide range of metabolic and respiratory disturbances, both acute and chronic, particularly in patients on mechanical ventilation.

The information obtained from an ABG analysis includes blood gas, acid base and electrolytes i.e. $\mathrm{pH}, \mathrm{pCO}_{2}, \mathrm{pO}_{2}$, oxygen saturation, base excess, bicarbonate levels, serum

'Financial or Other Competing Interest': None.

Submission 16-06-2017, Peer Review 01-03-2018,

Acceptance 08-03-2018, Published 19-03-2018.

Corresponding Author:

Dr. Bhabani Sankar Pati,

Plot No-45/896, Gayatri Vihar,

Baramunda, Bhubaneswar-751003, Odisha

E-mail: zulupati@gmail.com

DOI: $10.14260 /$ jemds $/ 2018 / 330$

\section{(c) $($ ) $९$}

sodium, potassium and total and ionised calcium. But arterial puncture apart from being painful and technically difficult carries the risk of complications like local haematoma, infection, thrombosis, embolisation or ischaemia of the digits.[1] On the other hand, capillary blood can be obtained by painless skin puncture to a depth of $1 \mathrm{~mm}$ using a lancet or automated incision device, is safe and requires minimal training.[2] Blood obtained from skin puncture is a mixture of blood from arterioles, venules and capillaries along with a variable contribution of interstitial and intracellular fluid. Due to relative high pressure on the arterial side of the circulation, this mixture contains a greater proportion of blood from arteriole side of capillary bed than from venule side. As long as tissue oxygen consumption and carbon dioxide production remains unchanged as in resting state, increasing blood flow through the capillary bed has the effect of reducing arteriovenous difference and hence the difference between arterial and capillary blood gas values.

The purpose of this study was to investigate the correlation between simultaneous arterial blood gas and arterialised earlobe blood samples and to establish whether $\mathrm{pH}$, partial pressure of oxygen $\left(\mathrm{PO}_{2}\right)$, partial pressure of carbon dioxide $\left(\mathrm{pCO}_{2}\right)$, base excess (BE) and bicarbonate $\left(\mathrm{HCO}_{3}-\right)$ values of arterialised earlobe blood samples could 
accurately predict their arterial blood gas analogues for patients with acute respiratory failure treated by mechanical ventilation in an intensive care unit (ICU).

\section{MATERIALS AND METHODS}

This was a descriptive study conducted from May 2015 to August 2016 in ICU of IMS and SUM Hospital, Bhubaneswar after due permission from the Hospital Ethical Committee and written informed consent from the patients' attendants. It is a combined medical and surgical ICU. A total of 82 patients, aged between 30 - 60 years of age, of both sexes on mechanical ventilation were selected. Patients with shock, severe sepsis, hypothermia or trauma in both hands were excluded from the study.

Blood sample was collected simultaneously from left radial artery and ear lobe. The ear lobe was arterialised using hot mops for 3 minutes, a bold puncture made with a lancet and blood was collected in pre-heparinised capillary tubes anaerobically without squeezing the ear lobe. Heparinisation was done by moving a metal bead to and fro inside the capillary tube with a magnet. Capillary tubes were then closed by means of rubber caps [Figure-1].

Arterial sample was collected from the left radial artery in pre-heparinised $2 \mathrm{~mL}$ syringes by $22-\mathrm{G}$ needle after modified Allen's test. All samples were collected from the patients after 12 hours of initiation of mechanical ventilation and the samples were analysed using a point-of-care blood gas analyser, Eschweiler BGA Plus E Combisys II.

\section{Statistical Analysis}

The statistical analysis was done using MedCalc V12.1.3. Categorical data were presented as percentage and continuous data as mean with standard deviation. BlandAltman plot was used to determine the magnitude of correlation. Regression analysis was done to find the correction factors using linear model.

\section{RESULTS}

18 patients were eliminated due to sampling error (repeated squeezing of finger, presence of air column). A total of 82 paired samples were analysed. The parameters observed were $\mathrm{pH}, \mathrm{pO}_{2}, \mathrm{pCO}_{2}$, bicarbonate in both the capillary and arterial samples. All data were tabulated, compared and analysed. The mean age of the patients was $42.36 \pm 8.40$ years of which there were 50 males and 32 females. Among them 48 patients were diagnosed with sepsis, 20 chronic obstructive pulmonary disease (COPD), 4 polytrauma and 10 neurological patients.

The Pearson's coefficient of correlation was calculated for arterial and capillary $\mathrm{PH}, \mathrm{PaO}_{2}$ and $\mathrm{pCO}_{2}$ and bicarbonate. Positive correlation was found between arterial and capillary values. The coefficients are depicted in Table 2, which shows all the values are significantly correlated.

On Bland-Altman's analysis of $\mathrm{pH}$ the mean difference was 0.01 , while limits of agreement (LOA) were between +0.07 to -0.05 units and all data were between two standard deviations. On Bland-Altman analysis for $\mathrm{PaO}_{2}$ the mean difference was $18.6 \mathrm{mmHg}$, while the limits of agreement (LOA) were between $14.2 \mathrm{mmHg}$ to $23.0 \mathrm{mmHg}$ and all the data were with two standard deviations. On Bland-Altman analysis for $\mathrm{pCO}_{2}$ mean difference was $-1.8 \mathrm{mmHg}$ and LOA was between $+6.2 \mathrm{mmHg}$ to $-10.1 \mathrm{mmHg}$ and bicarbonate we found mean difference was $-1.2 \mathrm{mmHg}$ and LOA was between $+7.1 \mathrm{mmHg}$ to $-12.1 \mathrm{mmHg}$. Regression analysis was done to find the convection formula for capillary to arterial. $\mathrm{PaO}_{2}$, it was $0.9\left(\mathrm{pCO}_{2}\right)+32.6 \mathrm{mmHg}$.

\begin{tabular}{|c|c|}
\hline Age (years) & $42.36 \pm 8.40$ \\
\hline Sex (Male: Female) & $50: 32$ \\
\hline \multicolumn{2}{|c|}{ Diagnosis n (\%) } \\
\hline Sepsis & $48(58.5)$ \\
\hline COPD & $20(24.4)$ \\
\hline Neurological & $10(12.2)$ \\
\hline Trauma & $4(4.9)$ \\
\hline Table 1. Demographics of Included Patients \\
\hline
\end{tabular}

\begin{tabular}{|c|c|c|c|}
\hline & Number & Correlation Coefficient & P value \\
\hline Art and Cap pH & 82 & 0.709 & $<0.001$ \\
\hline $\begin{array}{c}\text { Art and Cap } \\
\mathrm{pCO}_{2}\end{array}$ & 82 & 0.916 & $<0.001$ \\
\hline Art and Cap pO & 82 & 0.937 & $<0.001$ \\
\hline $\begin{array}{c}\text { Art and Cap } \\
\mathrm{HCO}_{3}\end{array}$ & 82 & 0.968 & $<0.001$ \\
\hline \multicolumn{3}{|c|}{ Table 2. Correlation Coefficient of Arterial and Capillary } \\
Blood Gas Parameters \\
\hline
\end{tabular}

Art: Arterial; Cap: Capillary; $\mathrm{pCO}_{2}$ : Partial pressure of carbon dioxide; $\mathrm{pO}_{2}$ : Partial pressure of oxygen; $\mathrm{HCO}_{3}$. Bicarbonate.

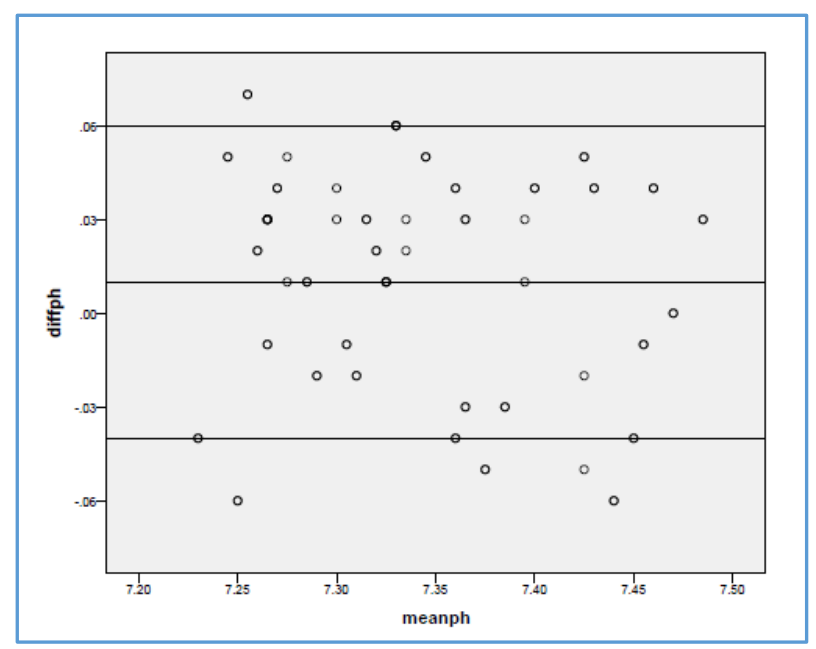

Figure 1

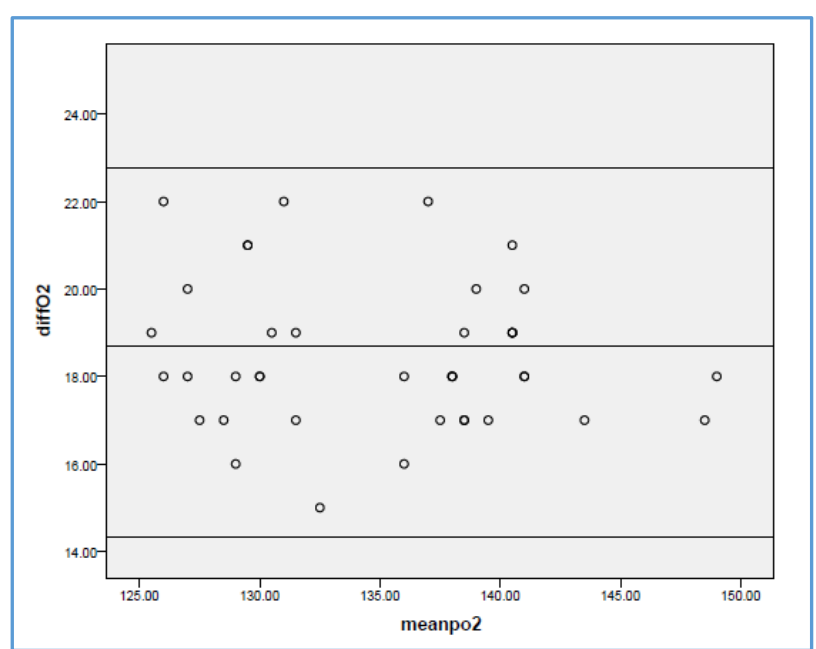

Figure 2 


\section{DISCUSSION}

Arterial blood gas though an essential part of ICU care is an invasive technique, painful and technically difficult. When an arterial line is not in place, capillary blood gas values seem an easier and feasible option for clinical monitoring and management decisions. There is a theoretical possibility that arterialisation strategies like pre-warming will reduce the $\mathrm{pO}_{2}$ difference between capillary and arterial blood. Our study aimed at comparing and correlating simultaneously obtained arterialised sample from ear lobe and radial artery and to compare the paired data using Bland-Altman analysis rather than simple comparison or lack of significant difference or presence of significant correlation methods as done in previous studies. The mean difference or bias obtained from Bland-Altman plot was judged clinically acceptable or unacceptable basing on maximum permissible difference as stated by The Clinical and Laboratory Standards Institute (CLSI). As per CLSI, the clinically acceptable difference between two simultaneous arterial samples analysed at the same time in two different analysers is delta $\mathrm{pH}=0.02$, delta $\mathrm{pCO}_{2}=3 \mathrm{mmHg}$, delta $\mathrm{pO}_{2}=7 \mathrm{mmHg}$ and delta bicarbonate $=4 \mathrm{mEq} / \mathrm{L}$.

The clinical value of capillary blood gas depends on the extent to which the $\mathrm{pH}, \mathrm{pCO}_{2}$ and $\mathrm{pO}_{2}$ of capillary blood accurately reflects that of the arterial blood. The use of arterialised earlobe blood sample for acid base status evaluation has been proposed almost 60 years back.[3] Techniques for sampling arterialised capillary blood from the finger pulp and the earlobe were described over twenty years ago. Being less invasive and easily accessible, arterialised ear lobe blood does not necessitate the risks of arterial punctures. Based on the postulation that provided sufficient vasodilatation can be attained locally using topical vasoactive cream on the earlobe, the arterialised earlobe oxygen tension mimics the arterial oxygen tension due to confluence of arterial and venous oxygen tension.[4] Still, even with resemblance depicted between arterial and earlobe sample values in normal subjects, this technique is not commonly sought due to lack of awareness and dubiety regarding its accuracy[5] Initial[3,6,7] or more recent[5] studies have concluded that the earlobe blood sampling might be authentic enough to replace arterial blood samples for clinical purposes. This inference is based mainly on positive and strong correlations that have been found between the two methods. However, most investigators have sought correlation using simple regression. This approach has portrayed the conclusion of most studies with statistical bias. In fact two recent studies using Bland and Altman ${ }^{[8]}$ analysis have stated that arterialised earlobe $\mathrm{pO}_{2}$ often undervalues arterial $\mathrm{pO}_{2}$, therefore making this method inapt for clinical evaluation. $[9,10]$ Various studies have shown good correlation between capillary blood, venous blood and arterial blood gas values in paediatric intensive care units.[11-13] The earlier studies either differed in the time or site of capillary sample collection or studied only one parameter or were multicentre which led to impediment in result interpretation.

In our study the analysis of paired samples for $\mathrm{pH}, \mathrm{pCO}_{2}$ and bicarbonate showed that the mean values were comparable and Pearson's correlation coefficient showed strong positive and statistically significant correlation. On Bland-Altman's analysis of $\mathrm{pH}$ the mean difference was 0.01 , while limits of agreement (LOA) were between +0.07 to -0.05 units and all data were between two standard deviations. On Bland-Altman analysis for $\mathrm{PaO}_{2}$ the mean difference was 18.6 $\mathrm{mmHg}$, while the limits of agreement (LOA) were between $14.2 \mathrm{mmHg}$ to $23.0 \mathrm{mmHg}$ and all the data were with two standard deviations. In all three cases, $97.5 \%$ data were found to be within 1.96 standard deviation of the mean difference or bias, which was clinically acceptable as per the CLSI standards. Since the $\mathrm{pCO}_{2}$ and bicarbonate were showing too large limits of agreement, they do not appear to be of having clinical value.

The main cause of underestimation of $\mathrm{pO}_{2}$ in arterialised capillary blood was insufficient arterialisation leading to a venous admixture, the effect of which depends upon the arteriovenous $\mathrm{pO}_{2}$ difference. Since most of the subjects had a normal $\mathrm{pO}_{2}$, the arteriovenous difference was large and a small venous admixture caused a large discrepancy. Our study results were in accordance with the results of Hughes et al,[14] Johnson $\mathrm{K}$ et al,[2] Escalante Kanashiro et al, Yang K et al,[15] Yildizdas et al,[16] Fajac I et al, Eaton $\mathrm{T}$, Rudkin $\mathrm{S}$ et al[17] and Zavorsky $\mathrm{G}$ et al[18] that suggests that capillary $\mathrm{pO}_{2}$ results have limited value and should be interpreted with caution.

The studies on neonates and young infants used capillary blood sample from heel stab after heel warming for 5 to 10 minutes ${ }^{[15]}$ or using a warmed surgical plastic device ${ }^{[2]}$ or histamine iontophoresis.[19] Finger stab is the preferred site for capillary sampling from children as per Harrison A et al and Escalante Kanashiro R et al..14] The studies of Janes $M$ et $\mathrm{al}^{[20]}$ and Barker DP et al[21] concluded that heel warming has no effect in terms of improved blood flow, an indication of ineffective arterialisation. The fingertip, ear lobe or the lower tip of earlobe are the usual sites of capillary sampling in adults and the most common method is application of a vasodilating cream to puncture site 5 to 10 minutes prior to sampling.

Meta-analysis by Gerald Zavorsky[18] at McGill University included 29 previously published studies, comprised 664 paired samples for comparison of earlobe capillary with arterial blood and 222 paired samples for comparison of fingertip capillary blood with arterial blood. Both were found to accurately reflect arterial $\mathrm{pH}, \mathrm{pCO}_{2}$ (mean difference was $0.07 \mathrm{mmHg} \pm 0.38$, though earlobe values were closer to arterial values than that of fingertip capillary samples) showed poor agreement between fingertip capillary and arterial $\mathrm{pO}_{2}$ (mean difference $10.3 \pm 15 \mathrm{mmHg}$, coefficient of determination 0.48 and residual standard error $15 \mathrm{mmHg}$ ) and better agreement in the earlobe sample (mean difference $2.1 \pm 6 \mathrm{mmHg}$, correlation of determination of 0.88 and residual standard error of $6 \mathrm{mmHg}$ ). Capillary blood sampled from fingertip is unsuited for assessment of oxygenation status[18] and long-term oxygen therapy.[20] These results were similar to that of our study. This contrasted with the studies of Dar K et al[22] and Pitkin A et al which suggested that capillary p02 values reflect arterial p02 sufficiently and could be used as a substitute for arterial blood not only to assess patient's acid base status, but also the oxygenation status. The oxygenation can be calculated based on the regression formula of $0.9 \mathrm{pO}_{2}$ (capillary) $+32.6 \mathrm{mmHg}$. 


\section{CONCLUSION}

Capillary blood gas analysis can be used to estimate the $\mathrm{pH}$ and $\mathrm{PaO}_{2}$, but may not be of value for calculating $\mathrm{pCO}_{2}$ or bicarbonate.

\section{REFERENCES}

[1] Barker WJ, Roberts JR, Hedges JR. Clinical procedures in emergency medicine. $3^{\text {rd }}$ edn. Philadelphia: WB Saunders 1998: p. 308-22.

[2] Johnson KJ, Cress GA, Conolly NW, et al. Neonatal Laboratory blood sampling: comparision of results from arterial catheter with those from an automated capillary device. Neonatal Network 2000;19(1):27-34.

[3] Langlands JH, Wallace WF. Small blood samples from ear-lobe puncture: a substitute for arterial puncture. Lancet 1965;2(7407):315-7.

[4] Fajac I, Texereau J, Rivoal V, et al. Blood gas measurement during exercise: a comparative study between arterialized earlobe sampling and direct arterial puncture in adults. Eur Respir J 1998;11(3):712-5.

[5] Pitkin AD, Roberts CM, Wedzicha JA. Arterialised earlobe blood gas analysis: an underused technique. Thorax 1994;49(4):364-6.

[6] Christoforides C, Miller JM. Clinical use and limitations of arterialized capillary blood for $\mathrm{PO} 2$ determination. Am Rev Respir Dis 1968;98(4):653-7.

[7] Spiro SG, Dowdeswell IR. Arterialized earlobe blood samples for blood gas tensions. $\mathrm{Br} \mathrm{J}$ Dis Chest 1976;70(4):263-8.

[8] Bland JM, Altman DG. Statistical methods for assessing agreement between two methods of clinical measurement. Lancet 1986;327(8476):307-10.

[9] Sauty A, Uldry C, Debétaz LF, et al. Differences in PO2 and PCO2 between arterial and arterialized earlobe samples. Eur Respir J 1996;9(2):186-9.

[10] Dall'Ava-Santucci J, Dessanges JF, Dinh-Xuan AT, et al. Is arterialized earlobe blood $\mathrm{PO} 2$ an acceptable substitute for arterial blood P02? Eur Respir J 1996;9(6):1329-30.

[11] Escalante-Kanashiro R, Tantalean-Da-Fieno J. Capillary blood gases in a pediatric intensive care unit. Crit Care Med 2000;28(1):224-6.
[12] Gennis PR, Skovron ML, Aronson ST, et al. The usefulness of peripheral venous blood in estimating acid-base status in acutely ill patients. Ann Emerg Med 1985;14(9):845-9.

[13] Harrison AM, Lynch JM, Dean JM, et al. Comparison of simultaneously obtained arterial and capillary blood gases in pediatric intensive care unit patients. Crit Care Med 1997;25(11):1904-8.

[14] Hughes JMB. Blood gas estimation from arterialised capillary blood versus arterial puncture: are they different? Eur Respir J 1996;9:184-5.

[15] Yang KC, SU BH, Tsai FJ, et al. The comparision between capillary blood sampling and arterial blood sampling in an NICU. Acta Paediatr Taiwan 2002;43(3):124-6.

[16] Yildizdas D, Yapicioglu H, Yilmaz HL, et al. Correlation of simultaneously obtained capillary, venous and arterial blood gases of patients in a paediatric intensive care unit. Arch Dis Child 2004;89(2):176-80.

[17] Eaton T, Rudkin S, Garett JE. The clinical utility of arterialised earlobe capillary blood in the assessment of patients for long-term oxygen therapy. Respir Med 2001;95(8):655-60.

[18] Zavorsky GS, Cao J, Mayo NE, et al. Arterial versus capillary blood gases: a meta-analysis. Respir Physiol \& Neurobiology 2007;155(3):268-79.

[19] Hunt CE. Capillary blood sampling in the infant: usefulness and limitations of two methods of sampling, compared with arterial blood. Pediatrics 1973;51(3):501-6.

[20] Janes M, Pinelli J, Landry S, et al. Comparision of capillary blood sampling using an automated incision device with and without warming the heel. J Perinatology 2002;22(2):154-8.

[21] Barker DP, Willets B, Cappendiik VC, et al. Capillary blood sampling: should the heels be warmed? Arch Dis Child (Fetal \& Neonatal Ed) 1996;74(2):139-40.

[22] Dar K, Williams T, Aitken R, et al. Arterial versus capillary sampling for analysing blood gas pressures. BMJ 1995;310(6971):24-5. 